\title{
Guillermo NúÑez Noriega (2009), Vidas vulnerables. Hombres indígenas, DIVERSIDAD SEXUAL Y VIH-SidA, MÉXICO: CIAD/CEDEMEX
}

\author{
Martín de la Cruz López-Moya
}

$\mathrm{E}$ l reporte de casos de VIH-Sida entre jornaleros agrícolas en el noroeste de México, muchos de ellos migrantes indígenas originarios del sureste mexicano, y el compromiso académico y personal por contribuir a la comprensión de las sexualidades, en particular de la sexualidad masculina, condujeron a Guillermo Núñez Noriega a iniciar esta aventura antropológica que luego quedó registrada en su libro Vidas vulnerables. Hombres indígenas, diversidad sexual y VIHSida. Así comienza el libro:

Los caminos de la vida son complejos, también los de la investigación. En ambos casos siempre surgen muchas rutas posibles, se toman decisiones y a menudo se llega a cruceros inesperados. Así es como llegué a este crucero de voces que son las historias de vida de cuatro hombres indígenas de diferentes pueblos del estado de Chiapas: zoque, tseltal, chol y tsotsil.

En las cuatro historias, Guillermo Núñez ofrece un retrato antropológico sobre la experiencia sexual

Martín de la Cruz López Moya, maestro en Antropología Social. Profesor e investigador del Centro de Estudios Superiores de México y Centroamérica de la Universidad de Ciencias y Artes de Chiapas, Cuerpo Académico Sociedad y Cultura en Fronteras. Temas de especialización: masculinidades, música popular, identidad y culturas urbanas. Correo electrónico: martindelacruzl@yahoo.com.mx. masculina y sus expresiones indeterminadas y disidentes entre hablantes de lenguas indígenas de Chiapas. En estos relatos autobiográficos, la voz y las visiones de los hombres entrevistados convergen con la mirada comprensiva del autor. Con sensibilidad antropológica y desde un posicionamiento político comprometido con la diversidad humana, el autor deja ver las vulnerabilidades en las vidas de estas personas, situaciones de fragilidad que pueden derivarse de los entrecruces entre sexualidad, etnicidad, migración y pobreza.

El eje que vertebra las historias de los cuatro hombres indígenas chiapanecos es el registro de la experiencia de su sexualidad individual y colectiva. Se trata de historias verdaderamente conmovedoras, las de:

[...] un hombre zoque masculino con prácticas homosexuales que deja su población y que labora como albañil entre el puerto de Veracruz y Cancún; un ex guerrillero zapatista bisexual que trabaja como jornalero agrícola itinerante en el noroeste de México; un joven tsotsil, transgénero, que labora como mesero en una cantina en San Cristóbal de Las Casas; y un hombre tseltal, ex militar, que migra a la ciudad de México y vive con VIH-Sida.

Los títulos de cada una de las historias narradas invitan desde el inicio a reflexionar sobre la condición 
de inestabilidad e indeterminación de la vida de sus protagonistas: "Debo regresar al primer sueño", "Todo lo que ha sido mi vida", "Siempre me he sentido en el aire" y "Mi lucha ahora es más complicada".

Aunque distintas, estas historias tienen en común los relatos que retratan la incomprensión de su sexualidad, situación que genera condiciones de vulnerabilidad en la vida de estas personas o de riesgo para la adquisición de enfermedades de transmisión sexual, con fuertes resonancias en la vida emocional y de sufrimiento personal. Se trata de vidas vulnerables por las siguientes razones: la discriminación y homofobia, una vez asumida la disidencia sexual y de género, y las representaciones dominantes de la sexualidad y genéricas en los contextos en que vivieron su infancia. Compartieron experiencias afectivas y sexuales homo-eróticas durante la pubertad antes de salir de sus comunidades; por vivir en condiciones de pobreza y de marginalidad, realidad que también padecen muchos millones de mexicanos; por vivir en situación de desplazamiento o de migración en Chiapas y en otras partes del territorio nacional; por desastres naturales, como la explosión del volcán Chichonal que a inicios de los años ochenta arrasó varios poblados de la región norte del estado o por su condición de marginalidad y búsqueda de empleo; o por conflictos de orden político o de control comunitario, como el levantamiento zapatista en 1994.

En estas historias de vida pueden leerse prácticas de discriminación y de homofobia, pobreza, marginación y racismo, como elementos que colocan a muchas personas en condiciones de vulnerabilidad en distintos momentos de su vida, particularmente en la adopción de prácticas sexuales de riesgo para la adquisición del VIH-Sida.

En las distintas secciones del libro se encuentran las respuestas a las interrogantes que animaron a Guillermo Núñez a llevar a cabo su investigación:

¿Cómo entender esa ausencia de la población indígena en la discusión académica, antropológica y política sobre la sexualidad y homosexualidad? ¿Por qué tampoco estaba presente la población indígena en la discusión sobre el sida? ¿Cuáles son las razones de carácter ideológico, o acaso teóricas, metodológicas o técnicas que explican la ausencia, marginación y negligencia de los estudios sobre hombres indígenas con prácticas homosexuales y su vulnerabilidad al VIH-Sida?

La sexualidad es observada desde una perspectiva teórica que la asume como una construcción social y cultural, no como una condición natural o una esencia con la que las personas nacen, sino que la experiencia sexual se vive de manera distinta en cada sociedad, de una generación a otra, se transforma a lo largo de la vida de las personas y constituye una expectativa social que se pone en escena en cada situación de interacción.

La historia de vida, como método de investigación, proporciona una densidad de información que puede ser presentada con un orden lógico y muestra los matices de la vida de las personas con quienes se dialoga. La complejidad humana se teje en cada relato en el que se narran las prácticas sexuales homo-eróticas. Hay una experiencia sexual y una manifestación de la cultura de la que participan cada uno de los protagonistas. En los relatos de vida se ponen de manifiesto memorias, tiempos, espacios, olores, sabores o los sonidos característicos de los entornos de cada uno, pero tienen como fondo las vivencias sexuales.

El método, la teoría y los registros etnográficos se complementan para mostrar una mirada antropológica renovada sobre los pueblos indígenas, aquella que privilegia más su condición humana activa y cambiante. Seres contemporáneos que mantienen relaciones sexuales con personas de su mismo y de otro sexo; seres que aman, sufren, luchan, como cualquier otro ser humano, pero que específicamente padecen distintas formas de discriminación y de exclusión. La perspectiva de Guillermo Núñez es distante de aquellos discursos que reproducen estereotipos sobre lo indígenaal verlos como "seres oscuros, atávicos, anclados en el pasado milenario, encerrados en sí mismos, apacibles, casi inmóviles y desmotivados"... o, como cuestiona el mismo autor, "seres primigenios, más cercanos que el resto de la población a una condición humana 
'natural', la cual se corresponde al orden moral." ¿No es acaso esta mirada otra forma velada de racismo? De paternalismo y desprecio que son alentados por distintos actores sociales gubernamentales y por otros agentes sociales que se asumen solidarios con las causas indígenas, donde la sexualidad "natural" y legitimada es la heterosexualidad, y cualquier expresión disidente como la homosexualidad es calificada como resultado de la influencia nociva del exterior.

La homosexualidad sigue siendo causa de discriminación en muchas partes del mundo. En Chiapas, la cultura pública relacionada con la homosexualidad masculina no escapa a ello. Anzilwinik - mujer hombrese nombra al hombre homosexual en tsotsil, nalanixuk nalanwinik - mitad mujer mitad hombre - en tojolabal, banchues en zoque, o bien, despectivamente, mampos en el sureste mexicano y en parte de Centroamérica. Se pueden agregar otras dos miradas que, colocadas en polos extremos, pueden derivar o bien en la celebración colectiva de la transgresión de los roles sexuales que han sido impuestos social e históricamente, o en el desprecio expresado con el uso de la violencia extrema contra cualquier expresión de disidencia sexual masculina. Por un lado, la celebración festiva y transgresora que feminiza los cuerpos de cientos de hombres cuando, vestidos con ropas de mujeres indígenas o no indígenas, participan durante peregrinaciones dedicadas a los santos patronos de barrios y pueblos de Chiapas: tal es el caso de los chuntaes en la Fiesta Grande en Chiapa de Corzo o del travestismo del que participan hombres durante la entrada de flores en honor a San Caralampio, en Comitán, entre muchas otras peregrinaciones de Chiapas, cuando usan prendas que apenas cubren sus cuerpos; travestismo que degrada o ennoblece o que puede provocar la imaginación erótica.

Por otro lado, se produjeron homicidios y vejaciones contra hombres homosexuales en Tuxtla Gutiérrez, la capital chiapaneca, y en sus alrededores, los cuales desde los años noventa fueron denunciados por organismos de derechos humanos; asesinatos sistemáticos de hombres homosexuales que no han sido del todo esclarecidos y que requirieron recomendaciones por parte de la Comisión Nacional de Derechos Humanos al gobierno estatal de entonces.

Este libro de Guillermo Núñez, como otros en los que él mismo ha reflexionado sobre la complejidad de la vivencia sexual, inspira muchas otras interpretaciones de la sexualidad masculina y de la vulnerabilidad. Nos interpela para pensar en la urgencia de acciones y políticas educativas que fomenten la conciencia y el reconocimiento de la diversidad sexual afectiva, amorosa y genérica; de acciones que favorezcan el desarrollo humano, como el empleo o los servicios de salud sexual y reproductiva, que tengan como meta mejorar la calidad de vida y el respeto a la dignidad de las personas, sin excluir a nadie por sus preferencias sexuales, pertenencia de clase, de género, étnica, orientación religiosa o política. Que alienten el respeto por la diversidad humana sin que esto signifique ignorar las desigualdades sociales en el acceso a recursos y a la calidad de vida. 